\title{
Hepatocellular carcinoma: epidemiology and risk factors
}

This article was published in the following Dove Press journal:

Journal of Hepatocellular Carcinoma

13 August 2014

Number of times this article has been viewed

\author{
Michael C Kew \\ Department of Medicine, Groote \\ Schuur Hospital and University of \\ Cape Town, Cape Town, South Africa
}

Correspondence: Michael C Kew Department of Medicine, Groote Schuur Hospital and University of Cape Town, Main Street, Observatory, Cape Town, South Africa
Abstract: Hepatocellular carcinoma is one of the major malignant tumors in the world today. The number of new cases of the tumor increases year by year, and hepatocellular carcinoma almost always runs a fulminant course and carries an especially grave prognosis. It has a low resectability rate and a high recurrence rate after surgical intervention, and responds poorly to anticancer drugs and radiotherapy. Hepatocellular carcinoma does not have a uniform geographical distribution: rather, very high incidences occur in Eastern and Southeastern Asia and in sub-Saharan Black Africans. In these regions and populations, the tumor shows a distinct shift in age distribution toward the younger ages, seen to greatest extent in sub-Saharan Black Africans. In all populations, males are more commonly affected. The most common risk factors for hepatocellular carcinoma in resource-poor populations with a high incidence of the tumor are chronic hepatitis B virus infection and dietary exposure to the fungal hepatocarcinogen aflatoxin $\mathrm{B}_{1}$. These two causative agents act either singly or synergistically. Both the viral infection and exposure to the fungus occur from early childhood, and the tumor typically presents at an early age. Chronic hepatitis $\mathrm{C}$ virus infection is an important cause of hepatocellular carcinoma in resource-rich countries with a low incidence of the tumor. The infection is acquired in adulthood and hepatocellular carcinoma occurs later than it does with hepatitis B virus-induced tumors. In recent years, obesity and the metabolic syndrome have increased markedly in incidence and importance as a cause of hepatocellular carcinoma in some resource-rich regions. Chronic alcohol abuse remains an important risk factor for malignant transformation of hepatocytes, frequently in association with alcohol-induced cirrhosis. Excessive iron accumulation in hereditary hemochromatosis and dietary iron overload in the Black African population and membranous obstruction of the inferior cava cause the tumor in a few countries.

Keywords: hepatocellular carcinoma, epidemiology, risk factors

\section{Epidemiology}

Hepatocellular carcinoma (HCC) is the most prevalent primary malignant tumor of the liver and is accepted as one of the major malignant diseases in the world today. Justification for this recognition is its high incidence in many of the most populous regions of the world and its increasing occurrence, in some other regions, as well as its often fulminant course, low resectability rate and high recurrence rate after resection, poor response to conservative management, and grave prognosis.

Worldwide, HCC is the fifth most common cancer in men and the seventh in women, with more than 748,000 new cases being diagnosed each year, accounting for $9.2 \%$ of all new global cancer cases (7.9\% in men; 3.7\% in women). ${ }^{1,2}$ Moreover, the number of new cases of $\mathrm{HCC}$ increases year by year. Of all patients worldwide with $\mathrm{HCC}, 84 \%$ 
live in resource-poor countries. ${ }^{1-3}$ Seventy percent of all new HCCs worldwide occur in Asia, with patients in the People's Republic of China accounting for $55 \%$ of liver cancer deaths each year. ${ }^{1}$ Most of the remaining tumors occur in sub-Saharan Black Africans. As worrying as these figures undoubtedly are, they are likely to be an underestimate of the true incidence, because, in sub-Saharan Africa, and perhaps in other resourceconstrained regions with a high incidence of HCC, the tumor is both underdiagnosed and underreported. ${ }^{3}$

HCC carries a particularly poor prognosis, ranking second in the world as a cause of cancer-related mortality, and has the shortest survival time of any cancer in both males and females. Almost without exception, those who develop HCC each year die within 12 months, attesting to its rapid progression and serious prognosis. ${ }^{1,2}$ The outlook is particularly grave in resource-poor countries, where the annual fatality ratio (0.96) is the highest of any human tumor. ${ }^{1,2}$

HCC does not have a uniform geographical distribution. In those regions with high incidences of the tumor - East and Southeast Asia, some of the Western Pacific islands, and sub-Saharan Africa - HCC accounts for more than $90 \%$ of all primary malignant tumors of the liver, with incidences that exceed 20 per 100,000 of the population per year., ${ }^{4,5}$ Mediterranean countries, such as Italy, Spain, and Greece, as well as Western Asia, Central America, the Caribbean, Eastern and Southeastern Europe, Romania, Peru, Czech Republic, Poland, and Russia, have incidences of between ten and 20 per 100,000 of the population per year. ${ }^{4,5}$ In the Americas, Great Britain, and remaining countries, the incidence is less than five, and often less than three, per 100,000 of the population per year, ${ }^{4,5}$ despite the incidences having increased appreciably in the USA and some other resourcerich countries during recent years.

The rising incidence of $\mathrm{HCC}$ has been attributed mainly to the increasing occurrence of two risk factors for the tumor, namely, chronic hepatitis $\mathrm{C}$ virus (HCV) infection and the burgeoning incidence of obesity, nonalcoholic fatty liver disease (NAFLD), and nonalcoholic steatohepatitis (NASH), and the other components of the metabolic syndrome. For example, the occurrence of HCC in the USA has tripled during the past 2 decades (from 1.4 per 100,000 in 1975-1977 to 4.8 per 100,000 in $2005-2008^{6,7}$ ), and this tumor, paralleling the epidemics of obesity and the metabolic syndrome, is now the most rapidly increasing cause of cancer deaths in that country. ${ }^{7,8}$

By contrast, the incidence of the tumor has decreased in some countries, for example Spain, Israel, and Latin American countries, even before any overt decrease in the known risk factors was recorded. ${ }^{9}$ In Taiwan, the universal vaccination of newborn babies against hepatitis $B$ virus (HBV) infection has already had a telling impact on the incidence of HBV-induced HCC.

Age-adjusted incidences of HCC per 100,000 persons per year for men and women (17.4 and 6.7, respectively) in resource-poor countries have been shown to be double those in resource-rich countries (8.7 and 2.8, respectively). ${ }^{5}$ The difference in incidence of the tumor between high-risk regions in resource-poor countries and low-risk regions of HCC in resource-rich countries may be as much as 100 -fold, one of the highest differences recorded among cancers. ${ }^{5}$

In countries with a high incidence of HCC, the tumor is not necessarily uniformly common throughout the countries. For example, in the People's Republic of China, HCC is most prevalent in the northeastern province of Jilin, in the Guangxi autonomous region, and along the eastern seaboard, ${ }^{11}$ and in Mozambique the highest incidences are in the eastern regions of Inhambane, Panda, Inharrime, and Morrumbene. ${ }^{12}$ Rural southern African Blacks have an approximately fourfold higher incidence of HCC than do their urban counterparts. ${ }^{13}$ Less obvious differences in incidence have been reported, especially in men, in European countries with an intermediate incidence of the tumor. ${ }^{14}$

In resource-rich countries, $\mathrm{HCC}$ is rare in patients under the age of 40 years and progressively increases in incidence in those in their 60s and 70s. ${ }^{2,9}$ Accordingly, the usual age at which the diagnosis is made in these countries ranges from the early 60 s to the middle 70 s. Elderly patients with HCC have been shown to have a poorer prognosis compared with nonelderly patients. ${ }^{15}$ This survival difference disappears when patients are compared in different treatment groups, suggesting a link between the shorter survival and undertreatment of elderly patients. ${ }^{15}$ In regions with a high incidence of the tumor in Asia, ${ }^{2,9}$ and even more so in sub-Saharan Africa, ${ }^{12,16}$ there is a distinct shift in the age distribution curve toward a younger age. This difference is seen to the greatest extent in Mozambican Shangaans, in whom 50\% of the patients are less than 30 years of age at the time they seek medical attention, and their average age at this time is 33 years. ${ }^{12}$ In Qidong County and the Guangxi autonomous region in the People's Republic of China, the mean age at the time of diagnosis of HCC is 40 years. ${ }^{16}$

In all geographical regions, males have a higher incidence of HCC than females, although the ratio is more skewed in regions with high risk of the tumor. ${ }^{1,2,13,14}$ The male:female ratio is approximately $3: 1$ or 4:1 in the Asia-Pacific region and in sub-Saharan Africa, as well as in medium-risk countries, ${ }^{1-4}$ 
compared with 2:1 in regions with low incidence of the tumor. ${ }^{1-4}$ Male predominance is more striking in relatively young age ranges in high-incidence regions, but in older age ranges in low-incidence regions. ${ }^{1-4}$

Caucasoid migrants from countries with a low incidence of HCC to those with a high incidence retain the low incidence of the tumor of their country of origin. ${ }^{14}$ These individuals almost always preserve their original behavioral patterns, and they generally enjoy a higher standard of living than do the natives of the region. By contrast, migrants from high-risk to low-risk regions of HCC show a decline in the incidence of the tumor with successive generations in the new country. ${ }^{17}$

\section{Risk factors for hepatocellular carcinoma}

The most common risk factors for HCC in resource-constrained geographical regions with high incidences of the tumor are chronic $\mathrm{HBV}$ infection and dietary exposure to the fungal toxin aflatoxin $\mathrm{B}_{1}\left(\mathrm{AFB}_{1}\right)$, the two often occurring together and potentiating each other's hepatocarcinogenic effects. In resource-rich regions with low incidences of $\mathrm{HCC}$, chronic $\mathrm{HCV}$ infection is a major risk factor. During recent years, the metabolic syndrome has become increasingly frequent and important as a cause of $\mathrm{HCC}$ in some resource-rich countries. Long-standing alcohol abuse remains a significant cause of the tumor in many countries, although it has received relatively little attention during recent times. Iron overload, either inherited or, in the case of Black sub-Saharan Africans, acquired, is a less common but nevertheless important cause of the tumor. Membranous obstruction of the inferior vena cava (MOIVC) causes HCC in a few regions only, and cigarette smoking plays a minor role in some countries. Cirrhosis, whatever its cause, is a risk factor for the development of the tumor. The role of cirrhosis per se in the etiology of HCC is considered elsewhere. ${ }^{18}$ Oral contraceptive steroids as a cause of the tumor remains uncertain.

\section{Chronic HBV infection}

$\mathrm{HBV}$ infection is one of the most prevalent infections in humans, with some 2 billion people worldwide (one-third of the global population) infected or having been infected with this virus. ${ }^{1}$ Moreover, HBV was one of the first viruses to be implicated as a cause of a human cancer, ${ }^{19}$ and evidence for its hepatocarcinogenicity is now beyond doubt. ${ }^{20}$ The virus is currently believed to be second only to tobacco smoking as an environmental carcinogen to which humans are exposed, causing approximately $55 \%$ of all HCCs worldwide. ${ }^{1}$
Of the approximately 400 million persons worldwide chronically infected with HBV, as many as one-quarter will develop the tumor. ${ }^{1,21}$ The incidence of HCC ranges from 340 to 804 per $100,000 \mathrm{HBV}$-positive males and 120 to 178 per 100,000 positive females per year, ${ }^{1,21}$ with odds ratios of 20.4 and 15.6, respectively, having been calculated. ${ }^{21}$

Chronic HBV infection and HCC have closely parallel geographical distributions, and chronic infection with the virus is implicated in the genesis of as many as $85 \%$ of the HCCs that occur with such high frequency in ethnic Chinese and Black African populations, ${ }^{20-21}$ both of which have high incidences of chronic HBV infection. In countries with a low or intermediate incidence of HCC, lower prevalences of hepatitis B virus surface antigen (usually less than $25 \%$ ) are found in patients with the tumor. ${ }^{20,22}$

In individuals chronically infected with HBV, host factors influence the risk of malignant transformation. Sex and age are important in this regard. Chronically infected males are at greater risk of developing HCC than infected females, ${ }^{19,20,23,24}$ the ratio being $2: 1$ to $3: 1$ in most populations, although it is appreciably higher in sub-Saharan Black Africans (5:1 or 6:1). ${ }^{20,24}$ In resource-rich countries, HCC is rare before the age of 40 years, irrespective of the HBV status. ${ }^{25}$ By contrast, in resource-poor countries, there is a distinct shift toward a younger age. In sub-Saharan Black Africans with HCC, $73.5 \%$ of patients under the age of 30 years have HBV-induced tumors, compared with $28.5 \%$ in those older than 60 years. $^{20}$

In populations with a high rate of $\mathrm{HBV}$-induced $\mathrm{HCC}$, the infection is predominantly acquired either perinatally or in infancy or early childhood. ${ }^{26-28}$ In ethnic Chinese populations, HBV infection occurs predominantly as a result of perinatal transmission from highly infectious hepatitis B e antigenpositive carrier mothers. ${ }^{25,28}$ Later, horizontal infection plays a lesser role. By contrast, in sub-Saharan Black Africans, horizontal spread of the virus between recently infected and hence highly infectious young siblings or playmates is the major source of infection, and perinatal transmission plays a far lesser role. ${ }^{26,28}$ The exact modes of horizontal spread of the infection among young Black children are not known. Weeping sores or ritual scarification of the skin by witch doctors using unsterile instruments may play a role. Bites by bloodsucking vectors, such as mosquitoes, bedbugs, and hard ticks, have been suggested as a possible route, but proof is not yet available. The differences in the modes of HBV infection between the two populations is attributed to differing frequencies of hepatitis B e antigen positivity: in ethnic Chinese women of childbearing age who are chronic carriers of $\mathrm{HBV}, 40 \%$ or 
more are hepatitis B e antigen-positive, and this is associated with a considerable risk of perinatal transmission, ${ }^{19,26}$ whereas, in Black African women of the same age, the prevalence of hepatitis B e antigen is appreciably lower. ${ }^{27,28}$

Children infected with HBV as neonates, infants, or very early in childhood have an $80 \%-90 \%$ chance of becoming chronic carriers of the virus, ${ }^{26,27}$ and it is these early-onset carriers of the virus that are at greatest risk for the later development of HCC.

Like all forms of carcinogenesis, $\mathrm{HBV}$-induced $\mathrm{HCC}$ is a complex, stepwise process that evolves over years. Although the virus may act alone, more usually it interacts with endogenous mutagens, such as reactive oxygen species, as well as with the inflammatory process generated by the host's immune response to the presence of the virus. It may also interact with a number of other environmental carcinogens, including $\mathrm{AFB}_{1}$ and $\mathrm{HCV}$, in causing the tumor.

Integration of HBV DNA into host DNA is thought to be a crucial step in the pathogenesis of HBV-related HCC. ${ }^{29,30}$ Integration occurs at multiple or single sites. The inserted DNA is always altered, usually by one or more deletions, but also by sequence rearrangements. The sites of integration are thought to be randomly distributed, although preferred sites do exist. Insertion of the viral DNA induces a series of changes in the flanking cellular sequences, including deletions, direct or inverted repeats, and chromosomal translocations. Two-thirds of the integrations occur at or near the cohesive overlap region between the direct repeat sequences DR1 and DR2. Integrated HBV DNA may also perturb the expression of cellular genes by activating transcription of these genes in trans. ${ }^{29,30}$

The HBx gene is often included in HBV integrants and remains functionally active, inducing many changes. ${ }^{29,30}$ It promotes cell cycle progression, inactivates negative growth regulators, and binds to and inhibits the expression of p53 tumor suppressor gene and other tumor suppressor genes. ${ }^{28-30}$ HBx protein also modulates transcription of methyl transferases, causing regional hypermethylation of DNA that results in silencing of tumor suppressor genes, or global hypermethylation that results in chromosomal instability. ${ }^{29,30}$ The virus also has antiapoptotic and proapoptotic effects. ${ }^{30,31}$ In addition, HBx gene may increase the expression of telomerase reverse transcriptase and telomerase activity, prolonging the lifespan of hepatocytes. It also interferes with nucleotide excision repair. Carboxyl-truncated $\mathrm{HBx}$ protein loses its inhibitory effects on cell proliferation. ${ }^{26}$ Dysregulation of IGF-11 enhances proliferation and antiapoptotic effects of oncogenes, giving rise to unregulated cell growth. The preS/S gene, when $3^{\prime}$ truncated, has transactivating functions..$^{30,31}$

\section{Chronic HCV infection}

Evidence for a causal role for $\mathrm{HCV}$ in hepatocarcinogenesis is a little more recent than that for HBV, but is equally compelling. In common with $\mathrm{HBV}$, the importance of $\mathrm{HCV}$ as a risk factor for HCC differs between resource-rich and resource-poor countries, but with $\mathrm{HCV}$ being an important infection and a major cause of HCC in the former rather than the latter regions. More than 170 million people in the world today, or $2.2 \%$ of the global population, are chronically infected with $\mathrm{HCV}^{32} \mathrm{~A}$ compelling characteristic of the virus is its ability to induce persistent infection in up to $75 \%$, or in up to $85 \%$ in some cases, despite a vigorous immune response by the host. Whether there is a specific and effective cellular response, and which pathways for virus elimination are compromised, remain disputed. The mechanism of the hepatic injury in acute and chronic HCV infection is unknown, but, because there is little evidence that the virus is directly cytopathogenic, it is believed that the damage to the liver is mediated by the host's cellular immune response to the infection.

The prevalence of chronic $\mathrm{HCV}$ infection ranges from $0.3 \%$ in Switzerland to more than $20 \%$ in Egypt. ${ }^{33-35}$ In addition, prevalences vary appreciably depending upon the subpopulation examined: injecting drug users have a prevalence of $60 \%-90 \%$; hemophiliacs 50\%-70\%; hemodialysis patients 15\%-60\%; and persons who received a blood transfusion before $19915 \%-10 \% .{ }^{33}$ In regions with a high incidence of $\mathrm{HCV}$ infection, $2 \%-2.4 \%$ of patients with $\mathrm{HCV}$-induced cirrhosis develop HCC each year of follow-up. Patients with chronic $\mathrm{HCV}$ infection are at a greater risk of malignant transformation than those with persistent HBV infection.

The ages of the patients influences progression of the infection: $5 \%$ of patients less than 40 years of age and $20 \%$ of those over 40 years of age progress to cirrhosis in less than 20 years. ${ }^{32-35}$ Approximately one-quarter of those with overt hepatitis will ultimately develop cirrhosis, and a significant proportion, usually but not invariably those with cirrhosis, progress to HCC. ${ }^{32-35}$ The interval between HCV infection and the development of HCC is typically 20 years or longer. The average age at which HCC is diagnosed in Japanese patients chronically infected with $\mathrm{HCV}$ is 62 years. ${ }^{34,35}$

Chronic HCV infection is the dominant cause of HCC in resource-rich countries. In Japan, Italy, and Spain, resourcerich countries with an intermediate incidence of $\mathrm{HCC}, \mathrm{HCV}$ accounts for as much as $83 \%$ of HCCs, and with odds ratios of 40 to $50 . .^{32-34}$ The annual rate of development of the tumor in patients with $\mathrm{HCV}$-induced $\mathrm{HCC}$ in most countries is between $2 \%$ and $8.9 \%$. The interval between $\mathrm{HCV}$ infection 
and the clinical recognition of HCC is typically 17 to 30 years, although a few patients present in as short a time as 5 to 10 years. ${ }^{32-37}$ In dying patients with $\mathrm{HCV}$ infection, $82 \%$ of deaths are caused by HCC. These patients are almost always approximately 10 years older than those with $\mathrm{HBV}$-induced HCC. The odds ratio of HCC developing in an individual infected with HCV has been calculated to be 11.5. ${ }^{32-37}$

The proportion of patients with HCC in whom HCV can be implicated as the cause shows a pronounced geographical variation, with risk factors differing between resource-rich and resource-constrained populations. Thus, in resource-rich countries, such as Japan, with an intermediate incidence of HCC, between $37.8 \%$ and $83 \%$ of the patients with HCC were shown to be chronically infected with $\mathrm{HCV}$, whereas, in regions with low incidence of the tumor, between $10.9 \%$ and $33 \%$ were chronically infected. ${ }^{34}$ During each year of follow-up, $2.4 \%$ of patients with $\mathrm{HCV}$-induced cirrhosis will develop HCC. ${ }^{35}$

Patients with $\mathrm{HCV}$-induced $\mathrm{HCC}$ are generally older than those with HBV-induced tumors: the difference in age in most countries is about 10 years, although it is 20 years in sub-Saharan Black Africans. ${ }^{37,38}$

The ways in which HCV causes HCC are unknown. Replicative intermediates of $\mathrm{HCV}$ do not integrate into chromosomal DNA.

Almost all HCV-related tumors arise in cirrhotic livers or in livers with chronic hepatitis. The virus causes hepatic inflammation by complex and not yet well-understood molecular pathways, including direct viral effects and indirect mechanisms involving cytokine pathways, oxidative stress, and steatosis induction. ${ }^{37}$ An increasing body of evidence recognizes the inflammatory response as pathogenically linked to the development of hepatic fibrosis, cirrhosis, and HCC. ${ }^{37}$

The heterogeneity of genetic/transcriptomic/proteomic events observed in hepatocytes expressing HCV proteins and HCV-related HCCs suggests that complex mechanisms underlie malignant transformation in $\mathrm{HCV}$-induced HCC..$^{32,35,38,39}$ These presumably act through convoluted virus/ host interactions, including HCV replication with host-cell cycles, apoptosis, proliferation, protein synthesis, lipid metabolism, and DNA damage response.

\section{Aflatoxins}

Aflatoxins are naturally occurring metabolites of the fungi Aspergillus flavus and Aspergillus parasiticus. They are structurally related difuranocoumarin derivatives, some of which are mutagenic and carcinogenic. These fungi are widely distributed in nature and are frequent contaminants of a number of staple foods, but particularly maize, ground nuts, rice, and sorghum. Aflatoxins pose serious health hazards to humans as a result of their toxic, teratogenic, mutagenic, and highly carcinogenic properties. ${ }^{40,41}$ Because atmospheric humidity and moisture content of plants are important in determining the growth of, and toxin production by, these molds, contamination of crops occurs mainly in subsistence-farming communities in tropical and subtropical climates with high humidity and temperature. ${ }^{42,43}$ In addition, prolonged storage of crops in hot and humid conditions promotes growth of the aflatoxin-producing fungi. Contamination is also likely to occur in regions where food drying and storage facilities are suboptimal, where technology and infrastructure necessary for food safety monitoring are inadequate, and where regulations to control exposure to molds are either nonexistent or unenforceable in practice. ${ }^{42,43}$ Most rural dwellers in such areas can afford only limited food variation, with the result that these staples comprise a significant portion of their diets.

Aflatoxins are the most common known noninfectious food-borne risk factors for HCC. It is estimated that 4.5 to 5.5 billion people worldwide are at risk of exposure to these toxins. ${ }^{44}$ The geographical regions involved are in sub-Saharan Africa, Eastern Asia, and parts of South America, with the association with aflatoxin exposure being closest in subSaharan Africa. ${ }^{42-44}$

Exposure to the toxins begins in utero as a consequence of transplacental transmission of the toxins, continues in the postnatal period by means of breast-feeding, and is perpetuated thereafter in the contaminated food eaten throughout life. ${ }^{45}$

It has been estimated that HCC may be attributed to exposure to $\mathrm{AFB}_{1}$ in between 25,200 and 155,000 people $\left(28.2 \%\right.$ of all cases of the tumor worldwide $\left.{ }^{44}\right)$, and that aflatoxins play a causative role in at least $4.6 \%$, and at most $28.2 \%$, of all cases of $\mathrm{HCC}$ worldwide. ${ }^{44}$ Reducing $\mathrm{AFB}_{1}$ exposure to non-detectable levels would thus significantly reduce the incidence of $\mathrm{HCC}$ cases in high-risk regions by this amount. ${ }^{40}$

Although the parent molecule of aflatoxin is harmless, it is converted by members of the cytochrome $\mathrm{p} 450$ superfamily into electrophilic intermediates that are mutagenic and carcinogenic. $^{40}$

$\mathrm{AFB}_{1}$ is the most potent known hepatocarcinogen. ${ }^{46,47}$ It is metabolized in the liver by $\mathrm{p} 450$ enzymes into $\mathrm{AFB}_{1-} 8,9-$ exo-epoxide, which is highly reactive and forms derivatives with DNA, RNA, and proteins, and which can react with the p53 tumor suppressor gene. ${ }^{48}$ In turn, $\mathrm{AFB}_{1}$ binds to DNA to form the predominant promutagenic 8,9 dihydro-8-(N7guanyl)-9-hydroxy $\mathrm{AFB}_{1}$ adduct. The latter can be converted into a more stable $\mathrm{AFB}_{1}$-formaminopyrimidine adduct, which 
causes guanine to thiamine transversion mutations. $\mathrm{AFB}_{1}{ }^{-}$ formaminopyrimidine, incorporated into double-stranded DNA, is mutagenic, whereas the dominant species in singlestranded DNA blocks DNA replication. ${ }^{49}$

The correlation between the degree of exposure to $\mathrm{AFB}_{1}$ and the incidence of HCC in humans is direct, with odds ratio for developing the tumor of 6.37:1.0 (range 3.74:1.0 to $10.86: 1.0) .{ }^{41,42}$ An arginine to serine ( $\mathrm{G}$ to $\mathrm{T}$ ) mutation at codon 249 of the p53 tumor suppressor gene is specific for exposure to aflatoxin and is detected in as many as $64 \%$ of patients with HCC. ${ }^{49-52}$ This mutation accounts for $90 \%$ of p53 mutations in $\mathrm{AFB}_{1}$-related HCC. ${ }^{50}$

\section{Synergistic interaction between AFB and $\mathrm{HBV}$ infection in hepatocarcinogenesis}

The first evidence that $\mathrm{AFB}_{1}$ and $\mathrm{HBV}$ might act synergistically in causing HCC was provided by a study in which individuals infected with HBV who lived in villages with a "high" consumption of $\mathrm{AFB}_{1}$ were shown to have a mortality rate ten times higher than that of individuals living in villages with a "low" consumption. ${ }^{53}$ A later study confirmed this observation by showing a 3.5-fold ( $95 \%$ confidence interval [CI]: $1.5-8.1)$ or a 6.0 -fold (95\% CI: 2-29) increase in the risk of $\mathrm{HCC}$ development in carriers of $\mathrm{HBV}$ exposed to $\mathrm{AFB}_{1,}$ in comparison with those not exposed. ${ }^{54}$ These clinical observations were confirmed in that HBsAg-transgenic mice developed $\mathrm{HCC}$ when exposed to $\mathrm{AFB}_{1}$, whereas their unexposed littermates did not. ${ }^{55}$

\section{The metabolic syndrome}

In recent years, the incidence of obesity has increased alarmingly in many resource-rich countries, none more so than in the USA. In the great majority of these obese individuals, the obesity is attributed to the metabolic syndrome. Paralleling this increase in obesity has been an increase in the incidence of HCC, and it has become increasingly evident that the burgeoning incidence of obesity in the inhabitants of resourcerich countries has been the dominant reason for the striking increase in the incidence of the tumor in these countries. ${ }^{56,57}$ For example, the occurrence of HCC in the USA has tripled during the past 2 decades, ${ }^{58}$ and the tumor, paralleling the epidemic of obesity, is now the most rapidly increasing cause of cancer deaths in that country. ${ }^{6}$ This increase in the number of cancer deaths in the USA has occurred at a time when it is estimated that $25 \%$ of the population (approximately 47 million people) meet the diagnostic criteria for the metabolic syndrome: the rates are 32\% in Mexican Americans, 24\% in European Americans, and 22\% in African Americans. ${ }^{59}$
A recent meta-analysis showed the relative risk for $\mathrm{HCC}$ to be 1.17 (95\% CI: 1.02-1.34) in those who were overweight (body mass index [BMI] 25-30 kg/m²) and 1.89 (95\% CI: $1.51-2.36)$ in those who were obese (BMI $\left.>30 \mathrm{~kg} / \mathrm{m}^{2}\right) .{ }^{60} \mathrm{In}$ the great majority of obese individuals in whom $\mathrm{HCC}$ has developed, the obesity has been attributed to the metabolic syndrome. This syndrome is defined as a constellation of metabolic and other abnormalities indicated by the presence of central obesity (BMI in excess of $30 \mathrm{~kg} / \mathrm{m}^{2}$ or increased waist circumference), plus at least two of the following clinical or biochemical components: fatty infiltration of the liver in the form of NAFLD or NASH; type 2 insulin resistance; hyperinsulinemia or overt type 2 diabetes mellitus; cirrhosis; hyperlipidemia; and systemic arterial hypertension. ${ }^{61}$

The incidence of the metabolic syndrome in different parts of the world ranges from $9 \%$ to $34 \%,{ }^{62,63}$ and it is estimated that as many as $90 \%$ of obese adults will develop the syndrome. NAFLD is currently the most common liver disease in resource-rich countries. ${ }^{64}$ Ten to twenty-six percent of patients with NAFLD progress to NASH, and $8.6 \%$ of the latter become cirrhotic, although the latter progression may take many years. ${ }^{65} \mathrm{Up}$ to $50 \%$ of patients with cirrhosis as a component of the syndrome, and a significant proportion of those without cirrhosis, develop HCC. Moreover, obesity in childhood has been shown to increase the risk of HCC in adulthood. ${ }^{65,66}$ Depending upon geographic location, socioeconomic circumstances, and ethnicity, the metabolic syndrome continues to increase in each of these locations and circumstances. The highest incidences are believed to occur in the USA, where it has been estimated that $34 \%$ of the adult population (32.2\% in males and $35.5 \%$ in females) currently meet the diagnostic criteria for the syndrome, ${ }^{67}$ and the number continues to increase.

Obesity is present in $33 \%$ to $100 \%$ of patients with NAFLD, and the risk of steatosis is appreciably higher in obese than in non-obese individuals. ${ }^{6,59}$ NAFLD is commonly associated with insulin resistance and hyperinsulinemia. ${ }^{65}$ Patients with steatosis are at risk for developing cirrhosis and HCC. ${ }^{64}$ Cohorts with NASH and cirrhosis have a risk of developing HCC, which is as high as $12.8 \%$ over a 3.2-year median follow-up period. ${ }^{68,69}$ Although NAFLD is currently the most common liver disease in resource-rich countries, the incidence of HCC complicating NAFLD is lower than that of HCC complicating NASH (4\%-27\%). ${ }^{64,65}$ The risk of HCC developing in patients with NASH-related cirrhosis rivals that in patients with $\mathrm{HCV}$-induced cirrhosis. ${ }^{70}$

Much remains to be learnt about the mechanisms by which obesity and the metabolic syndrome cause $\mathrm{HCC}$, 
although insulin resistance, increased tissue necrosis factor activity, alterations in serum lipids, NAFLD, and NASH play central roles.

\section{Alcohol abuse}

Abuse of alcohol is common in the Americas and Western Europe, and is increasing in Asia. More than 18 million adults in the USA (7\% of the USA adult population) abuse alcohol, a prevalence five times higher than that of chronic HCV infection, ${ }^{71,72}$ Chronic alcohol abuse (consumption in excess of $80 \mathrm{~g} /$ day) is complicated by the development of HCC. Such abuse for more than 10 years increases the chance of HCC development approximately fivefold..$^{72}$ Metaanalysis has shown a dose-response relationship between alcohol intake and $\mathrm{HCC}$ with relative risks of 1.19 (95\% CI: 1.12-1.27), 1.40 (95\% CI: 1.25-1.56), and 1.81 (95\% CI: 1.50-2.19) with intakes of alcohol of 25, 50, and $100 \mathrm{~g}$ per day, respectively. ${ }^{73,74}$ Alcohol abuse has been calculated to account for $32 \%$ of cases of HCC in the $\mathrm{USA}^{72}$ and $45 \%$ of the cases in Italy. ${ }^{75}$ With very few exceptions, patients who develop the tumor have alcohol-induced cirrhosis. ${ }^{76}$

Chronic alcohol consumption over at least 10 years significantly increases the risk for HCC development in patients chronically infected with either HCV or HBV, compared with patients with either viral infection who do not drink excess alcohol. Moreover, the tumor may occur at an earlier age in these patients. ${ }^{72}$

Patients with both alcohol abuse and diabetes mellitus have an odds ratio of developing HCC of 9.9, suggesting a synergistic interaction between the two factors in causing the tumor. ${ }^{77}$

\section{Iron overload}

Iron is ubiquitous in human cells and essential for their normal functioning, but, in excess, iron cannot be disposed of and is harmful to cells.

Only a small fraction of total body iron enters or leaves the body on a daily basis, ${ }^{78-80}$ with both iron absorption and loss being finely regulated and balanced. Hepatocytes are the main storage sites of iron, which is stored as ferric oxyhydroxyapatite, with one molecule of ferritin binding as many as 4,500 molecules of iron. ${ }^{78,79}$ Hepcidin, the most important regulator of systemic iron metabolism, is influenced by body iron stores, erythropoietic activity, and hypoxia, and plays the dominant role in controlling iron absorption. ${ }^{80}$ All circulating plasma iron is bound to transferrin. ${ }^{81}$ Most of the iron in humans exists either in storage as ferritin or as heme. ${ }^{82}$
Iron overload is generally defined as an increase in total body iron exceeding $5 \mathrm{~g}$. When the level of safe sequestration of the metal is exceeded, the storage protein is denatured, releasing large amounts of iron into the cytoplasm of the hepatocytes. Accordingly, the liver is the organ most likely to be afflicted by iron overload.

Evidence continues to accrue that iron accumulation in the liver is an important risk factor for the development of HCC. The amount and duration of exposure to excess iron is crucial to the development of hepatic damage, and, with few exceptions, the development of HCC in patients with hereditary hemochromatosis $(\mathrm{HH})$ occurs in the presence of cirrhosis. ${ }^{83}$

\section{Hereditary hemochromatosis}

$\mathrm{HH}$ is an autosomally recessive inherited disorder in individuals of Celtic descent. It is characterized by increased absorption of dietary iron that results in progressive deposition of the metal in multiple organs, but particularly in the liver. ${ }^{84}$ The disorder is the consequence of mutations in a number of genes concerned with iron absorption, ${ }^{84,85}$ the most common of which (in $70 \%-95 \%$ of patients) is homozygosity for the $\mathrm{C} 282 \mathrm{Y}$ mutation of the HFE gene. ${ }^{85,86}$ Inappropriately low secretion of hepcidin is postulated to be the mechanism causing the consequent iron overload. ${ }^{87}$

The incidence of $\mathrm{HCC}$ in patients with $\mathrm{HH}$ is $8 \%$ to $10 \%$ in most surveys, with the tumor accounting for as many as $45 \%$ of the deaths. ${ }^{86,87}$ Cirrhosis is present in almost all of the patients who develop the tumor. ${ }^{88}$

The hepatotoxic and hepatocarcinogenic potential of excessive iron is based upon its ability to generate reactive oxygen intermediates and oxidative stress, which damage DNA, lipids, and proteins and result in necrosis and apoptosis of hepatocytes. ${ }^{85,89}$ In addition, there is a close link between increased iron stores and type 2 insulin resistance, which promotes hepatocarcinogenesis (see the section "The metabolic syndrome").

It is currently not known if the direct hepatocarcinogenic effect of $\mathrm{HH}$ is solely attributed to the iron molecule, by virtue of its capacity to generate oxidative stress, form mutagenic hydroxyl radicles, and suppress host defense. Excess iron also acts indirectly through the induction of chronic inflammation leading to cirrhosis and hence to $\mathrm{HCC} .{ }^{89,90} \mathrm{HCC}$ has been documented to occur in iron-overloaded patients in the absence of cirrhosis, ${ }^{90,91}$ supporting the belief that increased hepatic iron may also directly cause or promote malignant transformation of hepatocytes. 
Oxidative stress leads to lipid peroxidation of unsaturated fatty acids in membranes of cells and organelles. Cytotoxic byproducts of lipid peroxidation, such as malondialdehyde and 4-hydroxy-2'-nonenol, are produced, and these impair cellular function and protein synthesis and induce DNA damage. ${ }^{85,89}$ Iron is also thought to be involved in the betacleavage of lipid hydroperoxide, producing biogenic aldehydes that interact with DNA. In addition, deoxyguanosine residues of DNA are hydroxylated by reactive oxygen intermediates to form 8-hydroxy-2' deoxyguanosine, a major promutagenic adduct that causes $\mathrm{G}$ : $\mathrm{C}$ to $\mathrm{T}$ :A transversions and DNA unwinding and strand breaks. In addition, free iron induces immunologic abnormalities that may decrease immune surveillance for malignant transformation. ${ }^{85,89}$

\section{Dietary iron overload in Black Africans}

Dietary iron overload has been described in rural Black Africans in at least 15 sub-Saharan African countries. The condition may affect as many as $15 \%$ of the adult male population. ${ }^{90}$ It results from the consumption, over time, of large volumes of homemade beer, which has a high iron content as a consequence of it being homebrewed in iron drums or pots. ${ }^{90}$ The high iron content $(46-82 \mathrm{mg} / \mathrm{L})$ of this beer contrasts with that of commercial beers (less than $0.5 \mathrm{mg} / \mathrm{L}$ ). ${ }^{92}$ During the fermentation of the sorghum or other locally grown crops, the $\mathrm{pH}$ of the ferment decreases to a very low level ( $\mathrm{pH} 3.5-3.8)$, leaching iron from the container into the contents. ${ }^{92}$ The iron is in an ionized, highly bioavailable form. Serum iron values in the iron-overloaded individuals range between 32 and 519 $\mathrm{mmol} / \mathrm{g}$ dry weight (geometric mean $128 \mathrm{mmol} / \mathrm{g}$ ). Hepatic iron concentrations greater than $1 \%$ dry weight are present in $43.2 \%$ of the males and $16.6 \%$ of the females. ${ }^{90}$ Portal fibrosis is present in $58 \%$ of the individuals, and cirrhosis in $10 \%$. Females are protected against the iron overload as a result of iron losses during menstruation and childbearing.

Dietary iron overload may be complicated by the development of HCC, with the relative risk ranging from 1.5 to 76.8 , with a mean figure of $10.6 \% .^{91}$

The association between the iron overload and the development of HCC has been confirmed in studies in rats fed a high-iron diet. After 15 months, the iron-loaded liver developed HCC in the absence of cirrhosis. ${ }^{92}$

\section{Membranous obstruction of the inferior vena cava}

Membranous obstruction of the inferior vena cava (MOIVC) is an occlusive lesion of the inferior vena cava, usually complete, but occasionally with a small central opening, which is located close to the entrance of the inferior vena cava into the right atrium or just below the level of the diaphragm. Although usually in the form of a membrane of variable thickness, it may take the form of a fibrotic occlusion of variable length. The condition occurs more often in men than in women, and most patients are in their 30s, 40s, or $50 \mathrm{~s}$. MOIVC is rare in most countries, but occurs more frequently in Southern Africa, India, Japan, Nepal, the People's Republic of China, and Korea. ${ }^{93}$ For example, it occurs in $4 \%$ of subSaharan Black Africans. ${ }^{93}$ It is uncertain whether the lesion is a congenital vascular anomaly or the result of organization of a thrombus in the hepatic portion of the inferior vena cava. ${ }^{93}$ The lesion impedes hepatic venous drainage, causing chronic hepatic venous congestion and centrilobular fibrosis of the liver.

MOIVC may be complicated by the development of HCC. The risk varies between different geographical regions, being highest in South African Blacks, with a risk of $40 \%$ to $48 \%$. ${ }^{94}$ Incidences in countries other than South Africa range between $4.7 \%$ and $23 \% .{ }^{94,95}$ African patients with HCC complicating MOIVC are younger than those with the tumor but without the obstruction resulting from MOIVC. ${ }^{94}$

The reason for the malignant transformation is unknown, although it is not thought to be a direct consequence of the occlusive lesion. Rather, the centrilobular necrosis and regeneration resulting from the hepatic venous hypertension and congestion, by acting as a tumor promoter, predisposes to one or more environmental carcinogens prevalent in those countries where HCC often complicates MOIVC. This belief is supported by the geographical distribution of the complicating HCC in Southern Africa. ${ }^{94,96}$

\section{Tobacco smoking}

A relatively small number of studies have addressed the question of smoking as a cause of HCC. ${ }^{97,98}$ Nevertheless, these have shown increased odds ratios for the development of the tumor in cigarette smokers. For example, odds ratios of 1.7 (95\% CI: 1.0-2.9) in current smokers compared with nonsmokers ${ }^{97}$ and 1.56 (95\% CI: 1.29-1.87) in current smokers compared with never-smokers ${ }^{98}$ have been documented, as has a ratio of 1.49 (95\% CI: $1.06-2.10)$ in former smokers compared to never-smokers. ${ }^{98}$ On the basis of studies of the odds ratios, some authorities have not regarded smoking as a risk factor because of the uncertainty introduced by the confounding effects of alcohol consumption and HBV and HCV infections. ${ }^{99}$ However, the International Agency for Research in Cancer $^{99}$ regards smoking as a risk factor, and most authorities concur with this conclusion. ${ }^{99}$ 


\section{Oral contraceptive steroids}

Although a number of studies devoted to the hepatocarcinogenicity of oral contraceptives have been published, the evidence available in this regard is inconclusive at present. ${ }^{100}$

\section{Disclosure}

The author reports no conflicts of interest in this work.

\section{References}

1. Ferlay J, Shin H, Bray F, Forman D, Mathers C, Parkin DM. Estimates of worldwide burden of cancer in 2008: GLOBOCAN 2008. Int J Cancer. 2010;127:2893-2917.

2. Jemal A, Bray F, Center MM, et al. Global cancer statistics. Carcinogenesis. 2011;61:69-90.

3. Kew MC. Hepatocellular Carcinoma in Sub-Saharan Africa. Trafford Publishing (North America and International); 2012:8-10.

4. GLOBOCAN. Lyon: International Agency for Research on Cancer (IARC). Available from: http://www-dep.iarc.fr. Accessed.

5. Mortality Database. WHO Statistical Information System. Geneva: World Health Organization; 2008. Available from: http://www.who. int/whosis. Accessed.

6. Altekruse SF, McGlynn KA, Reichman ME. Hepatocellular carcinoma incidence, mortality, and survival trends in the United States from 1975 to 2005. J Clin Oncol. 2009;27:1485-1491.

7. Mittal S, El-Serag HB. Epidemiology of hepatocellular carcinoma: consider the population. J Clin Gastroenterol. 2013;47:Suppl:S2-S6.

8. Llovet JM, Burroughs A, Bruix J. Hepatocellular carcinoma. Lancet. 2003;362:1907-1917.

9. Bosch FX, Ribes J, Borràs J. Epidemiology of primary liver cancer. Semin Liver Dis. 1999;19:271-285.

10. Chang MH, Chen CJ, Lai MS, et al. Universal hepatitis B vaccination in Taiwan and the incidence of hepatocellular carcinoma in children. Taiwan Childhood Hepatoma Study Group. New Engl J Med. 1997;336: 1855-1859.

11. Chinese Academy of Medical Sciences. Atlas of Cancer Mortality in the People's Republic of China. Beijing: China Map Press; 1981.

12. Prates MD, Torres FO. A cancer survey in Lourenço Marques, Portuguese East Africa. J Natl Cancer Inst. 1965;35:729-757.

13. Kew MC, Rossouw E, Hodkinson HJ, Paterson A, Dusheiko GM, Whitcutt JM. Hepatitis B virus status of southern African Blacks with hepatocellular carcinoma: comparison between rural and urban patients. Hepatology. 1983;3:65-68.

14. Bosch FX. Global epidemiology of hepatocellular carcinoma. In: Okuda K, Tabor E, editors. Liver Cancer. New York: Churchill Livingstone; 1997:13-28.

15. Pignata S, Gallo C, Daniele B, et al; CLIP Investigators. Characteristics at presentation and outcome of hepatocellular carcinoma (HCC) in the elderly. A study of the Cancer of the Liver Italian Program (CLIP). Crit Rev Oncol Hematol. 2006;59:243-249.

16. Kew MC, Macerollo P. The effect of age on the role of hepatitis B virus in hepatocellular carcinoma in blacks. Gastroenterology. 1988;94: 439-442.

17. Pisani P, Parkin DM, Bray F, Ferlay J. Estimates of the worldwide mortality from 25 cancers. Int J Cancer. 1999;10: 870-873.

18. Kew MC. The role of cirrhosis in the etiology of hepatocellular carcinoma. $J$ Gastrointest Cancer. 2014;45:12-21.

19. Blumberg BS, Larouzé B, London WT, et al. The relation of infection with the hepatitis B agent to primary hepatic carcinoma. Am J Pathol. 1975;81:669-682.

20. Kew MC. Epidemiology of chronic hepatitis B virus infection, hepatocellular carcinoma, and hepatitis B virus-induced hepatocellular carcinoma. Pathol Biol (Paris). 2010;58:273-277.

21. Parkin DM, Bray F, Ferlay J, Pisani P. Estimating the world cancer burden: Globocan 2000. Int J Cancer. 2001;94:153-156.
22. Nguyen VTT, Amin J, Law M, et al. Predictors and survival in hepatitis $B$ virus-related hepatocellular carcinoma in New South Wales, Australia. J Gastroenterol Hepatol. 2008;24:436-442.

23. Okuda K. Clinical aspects of hepatocellular carcinoma: analysis of 134 cases. In: Okuda K, Peters RL, editors. Hepatocellular Carcinoma. New York: John Wiley and Sons: 387-436.

24. Higginson J. The geographical pathology of primary liver cancer. Cancer Res. 1963;23:1624-1633.

25. Kew MC, Dos Santos HA, Sherlock S. Diagnosis of primary cancer of the liver. Br Med J. 1971;4:408-411.

26. Beasley RP, Hwang LY. Hepatocellular carcinoma and hepatitis B virus. Semin Liver Dis. 1984;4:113-121.

27. Botha JF, Ritchie MJ, Dusheiko GM, Mouton HW, Kew MC. Hepatitis B virus carrier state in black children in Ovamboland: role of perinatal and horizontal infection. Lancet. 1984;2:1210-1212.

28. [No authors listed]. Hepatocellular carcinoma: differences between high and low incidence regions. Lancet. 1987;2:1183-1184.

29. Shafritz DA, Shouval D, Sherman HI, Hadziyannis SJ, Kew MC. Integration of hepatitis B virus DNA into the genome of liver cells in chronic liver disease and hepatocellular carcinoma. Studies in percutaneous liver biopsies and post-mortem tissue specimens. $N$ Engl $J$ Med. 1981;305:1067-1073.

30. Kew MC. Hepatitis $B$ virus $x$ protein in the pathogenesis of hepatitis B virus-induced hepatocellular carcinoma. $J$ Gastroenterol Hepatol. 2011;26;Suppl 1:144-152.

31. Feitelson MA, Bonamassa B, Arzumanyan A. The roles of hepatitis B virus-encoded $\mathrm{X}$ protein in virus replication and the pathogenesis of chronic liver disease. Expert Opin Ther Targets. 2014;18:293-306.

32. Kew MC, François G, Lavanchy D, et al; Viral Hepatitis Prevention Board. Prevention of hepatitis C virus infection. JViral Hepat. 2004;11: 198-205.

33. Hutin Y, Kitler ME, Dore G, et al. Global burden of disease for hepatitis C. J Clin Pharmacol. 2003;43:20-29.

34. Hepatitis Viruses. Lyon: International Agency for Research on Cancer (IARC); 1994:165-221.

35. Kew MC. Hepatitis $\mathrm{C}$ virus and hepatocellular carcinoma in developing and developed countries. Viral Hepatit Rev. 1998;4:259-269.

36. Bruno S, Silini E, Crosignani A, et al. Hepatitis C virus genotypes and risk of hepatocellular carcinoma in cirrhosis: a prospective study. Hepatology. 1997;25:754-758.

37. Zampino R, Marrone E, Restivo L, et al. Chronic HCV infection and inflammation: clinical impact on hepatic and extra-hepatic manifestations. World J Hepatol. 2013;5:528-540.

38. Kew MC. Hepatitis C virus and hepatocellular carcinoma. FEMS Microbiol Rev. 1994;14:211-219.

39. Di Bisceglie AM, Simpson LH, Lotze MT, Hoofnagle JH. Development of hepatocellular carcinoma among patients with chronic liver disease due to hepatitis C viral infection. J Clin Gastroenterol. 1994;19: 222-226.

40. International Agency for Research on Cancer. Some Traditional Herbal Medicines, Some Mycotoxins, Naphthalene and Styrene. IARC Monographs on the Evaluation of the Carcinogenic Risks to Humans. Vol 82. Lyon: IARC Press; 2002.

41. Williams JH, Phillips TD, Jolly PE, Stiles JK, Jolly CM, Aggarwal D. Human aflatoxicosis in developing countries: a review of toxicology, exposure, potential health consequences, and interventions. Am J Clin Nutr. 2004;80:1106-1122.

42. Strosnider H, Azziz-Baumgartner E, Banziger M, et al. Workgroup report: public health strategies for reducing aflatoxin exposure in developing countries. Environ Health Perspect. 2006;114:1898-1903.

43. Liu Y, Chang CC, Marsh GM, Wu F. Population attributable risk of aflatoxin-related liver cancer: systematic review and meta-analysis. Eur J Cancer. 2012;48;2125-2136.

44. Wild CP, Pionneay F, Montesana R, et al. Aflatoxin detected in milk by immunoassay. Vir Hepatit Rev. 1998;4;259-269.

45. Wild CP, Turner PC. The toxicology of aflatoxins as a basis for public health decisions. Mutagenesis. 2002;17:471-481. 
46. Bressac B, Kew MC, Wands J, Ozturk M. Selective G to T mutations of p53 gene in hepatocellular carcinoma from southern Africa. Nature. 1991;350:429-431.

47. Brown RL, Chen ZY, Cleveland TE, Russin JS. Advances in the development of host resistance in corn to aflatoxin contamination by Aspergillus flavus. Phytopathology. 1999;89:113-117.

48. Hsu IC, Metcalf RA, Sun T, Welsh JA, Wang NJ, Harris CC. Mutational hotspot in the p53 gene in human hepatocellular carcinomas. Nature. 1991;350:427-428.

49. Kirk GD, Camus-Randon AM, Mendy M, et al. Ser-249 p53 mutations in plasma DNA of patients with hepatocellular carcinoma from The Gambia. J Natl Cancer Inst. 2000;92:148-153.

50. Gouas D, Shi H, Hainaut P. The aflatoxin-induced TP53 mutation at codon 249 (R249S): biomarker of exposure, early detection and target for therapy. Cancer Lett. 2009;286:29-37.

51. Kew MC. Aflatoxins as a cause of hepatocellular carcinoma. J Gastrointest Liver Dis. 2013;22:306-310.

52. Yeh FS, Mo CC, Yen RC. Risk factors for hepatocellular carcinoma in Guangxi, People's Republic of China. Natl Cancer Inst Monogr. 1989;69:47-48

53. Yu MW, Lien JP, Chiu YH, Santella RM, Liaw YF, Chen CJ. Effect of aflatoxin metabolism and DNA adduct formation on hepatocellular carcinoma among chronic hepatitis B carriers in Taiwan. J Hepatol. 1997;27:320-330.

54. Ming L, Thorgeirrson SS, Gail MH, et al. Dominant role of hepatitis B and cofactor role of aflatoxin in hepatocarcinogenesis in Qidong, China. Hepatology. 2002;36:1214-1220.

55. Sell S, Hunt JM, Dunsford HJ, Chisari FV. Synergy between hepatitis $B$ virus expression and chemical hepatocarcinogens in transgenic mice. Cancer Res. 1991;51:1278-1285.

56. Calle EE, Rodriguez C, Walt-Thurmond K, et al. Over-weight, obesity, and cancer risk. Lancet Oncol. 2002;348:625-1638.

57. Bianchini F, Kaaks R, Vainio H. Overweight, obesity, and cancer risk. Lancet Oncol. 2002;3:565-574.

58. El-Serag HB. Hepatocellular carcinoma. N Engl J Med. 2011;365: $1118-1127$.

59. Borena W, Strohmaier S, Lukanova A, et al. Metabolic risk factors and primary liver cancer in a prospective study of 578,700 adults. Int J Cancer. 2012;131:193-200.

60. Welzel TM, Graubard BI, Zeuzem S, El-Serag HB, Davila JA, McGlynn KA. Metabolic syndrome increases the risk of primary liver cancer in the United States: a study in the SEER-Medicare database. Hepatology. 2011;54:463-471.

61. Marchesini G, Brizi M, Morselli-Labate AM, et al. Association of nonalcoholic fatty liver disease with insulin resistance. Am J Med. 1999; $107: 450-455$.

62. Takumatso S, Noguvchi N, Kurdole K, et al. Influence of risk factors for metabolic syndrome and in alcoholic fatty liver disease on the prognosis and progress of hepatocellular carcinoma. Hepatogastroenterology. 2008;55:609-614.

63. Ford ES, Giles WH, Mokdad HH. Prevalence of metabolic syndrome among US Adults. Diabetes Care. 2004;2(10):2444-2449.

64. Lazo M, Clark JM. The epidemiology of nonalcoholic fatty liver disease: a global perspective. Semin Liver Dis. 2008;28:339-350.

65. Nobili V, Alisi A, Grimaldi C, et al. Non-alcoholic fatty liver disease and hepatocellular carcinoma in a 7-year-old obese boy: coincidence or comorbidity? Pediatr Obes. Epub December 3, 2013.

66. Ervin RB. Prevalence of metabolic syndrome among adults 20 years of age and over, by sex, age, race and ethnicity, and body mass index: United States, 2003-2006. Natl Health Stat Report. 2009;(13):1-7.

67. Adams LA, Lymp JF, St Sauver J, et al. The natural history of nonalcoholic fatty liver disease: a population-based cohort study. Gastroenterology. 2005;129:113-121.

68. Ascha MS, Hanouneh IA, Lopez R, Tamimi TA, Feldstein AF, Zein NN. The incidence and risk factors of hepatocellular carcinoma in patients with nonalcoholic steatohepatitis. Hepatology. 2010;51:1972-1978.
69. Schlesinger S, Aleksandrova K, Pischon T, et al. Abdominal obesity, weight gain during adulthood and risk of liver and biliary tract cancer in a European cohort. Int J Cancer. 2013;132:645-657.

70. Matteoni CA, Younossi ZM, Gramlich T, Boparai N, Liu YC, McCullough AJ. Nonalcoholic fatty liver disease: a spectrum of clinical and pathological severity. Gastroenterology. 1999;116:1413-1419.

71. Grant B, Harford T, Dawson D, et al. Alcohol abuse and dependence: United States 1992. Alcohol Health Res World. 1994;18:243-248.

72. Morgan TR, Mandayam S, Jamal MM. Alcohol and hepatocellular carcinoma. Gastroenterology. 2004;127(5 Suppl 1):S87-S96.

73. Boffetta P, Hashibe M. Alcohol and cancer. Lancet Oncol. 2006;7: 149-156.

74. Chiesa R, Donato F, Tagger A, et al. Etiology of hepatocellular carcinoma in Italian patients with and without cirrhosis. Cancer Epidemiol Biomarkers Prev. 2000;9:213-216.

75. Donato F, Tagger A, Chiesa R, et al. Hepatitis B and C virus infection, alcohol drinking, and hepatocellular carcinoma: a case-control study in Italy. Brescia HCC Study. Hepatology. 1997;26;579-584.

76. Nzeako UC, Goodman ZD, Ishak KG. Hepatocellular carcinoma in cirrhotic and noncirrhotic livers. A clinico-histopathologic study of 804 North American patients. Am J Clin Pathol. 1996;105:65-75.

77. Donato F, Tagger A, Gelatti U, et al. Alcohol and hepatocellular carcinoma: the effect of lifetime intake and hepatitis virus infections in men and women. Am J Epidemiol. 2002;155:323-331.

78. Andrews NC. Disorders of iron metabolism. N Engl J Med. 1999;341: 1986-1995.

79. Huang $X$. Iron overload and its association with cancer risk in humans: evidence for iron as a carcinogenic metal. Mutat Res. 2003;533: 152-171.

80. McCord JM. Iron, free radicals, and oxidative injury. Semin Hematol. 1998;35:5-12.

81. Greene CM, Varley RB, Lawless MW. MicroRNAs and liver cancer associated with iron overload: therapeutic targets unravelled. World $J$ Gastroenterol. 2013;19:5212-5226.

82. Ludwiczek E, Aigner I, Theurl I, Weiss G. Cytokine-mediated regulation of iron transport in human monocytic cells. Blood. 2003;101: $4148-4154$.

83. Toth I, Yuan L, Rogers JT, Boyce H, Bridges KR. Hypoxia alters iron-regulatory protein-I binding capacity and modulates cellular iron homeostasis in human hepatoma and erythroleukemia cells. $J$ Biol Chem. 1999;274:4467-4473.

84. Toyokuni S. Role of iron in carcinogenesis: cancer as a ferrotoxic disease. Cancer Sci. 2009;100:9-16.

85. Haddow JE, Palomaki GE, McClain M, Craig W. Hereditary haemochromatosis and hepatocellular carcinoma in males: a strategy for estimating the potential for primary prevention. J Med Screen. 2003;10:11-13.

86. Strohmeyer G, Niederau C, Stremmel W. Survival and causes of death in hemochromatosis. Observations in 163 patients. Ann NY Acad Sci. 1988;526:245-257.

87. Powell LW, Yapp TR. Hemochromatosis. Clin Liv Dis. 2000;4: 211-228.

88. Francanzani AL, Conte D, Fraquelli M, et al. Increased cancer risk in a cohort of 230 patients with hereditary hemochromatosis in comparison to matched control patients with non-iron-related chronic liver disease. Hepatology. 2001;33:647-651.

89. Olnyk JK, St Pierre TG, Britton RS, Brunt EM, Bacon BR. Duration of hepatic iron exposure increases the risk of significant fibrosis in hereditary hemochromatosis: a new role for magnetic resonance imaging. Am J Gastroenterol. 2005;100:837-841.

90. Kowdley KV. Iron, hemochromatosis, and hepatocellular carcinoma. Gastroenterology. 2004;127(5 Suppl 1):S579-S586.

91. Hassan MM, Hwang LY, Hatten CJ, et al. Risk factors for hepatocellular carcinoma: synergism of alcohol with viral hepatitis and diabetes mellitus. Hepatology. 2002;36:1206-1213.

92. Kew MC, Asare GA. Dietary iron overload in the African and hepatocellular carcinoma. Liver Int. 2007;27:735-741. 
93. Kew MC, Hodkinson HJ. Membranous obstruction of the inferior vena cava and its causal relation to hepatocellular carcinoma. Liver Int. 2006;26:1-7.

94. Simson IW. Membranous obstruction of the inferior vena cava and hepatocellular carcinoma in South Africa. Gastroenterology. 1982;82: 171-178.

95. Gwon D 2nd, Ko GY, Yoon HK, et al. Hepatocellular carcinoma associated with membranous obstruction of the inferior vena cava: incidence, characteristics, and risk factors and clinical efficacy of TACE. Radiology. 2010;254:617-626.

96. Kew MC, McKnight A, Lakis N, et al. Membranous obstruction of the inferior vena cava by tumor in hepatocellular carcinoma. Trop Gastroenterol. 1989;10:173-178.
97. Chuang SC, La Vecchia C, Boffetta P. Liver cancer: descriptive epidemiology and risk factors other than $\mathrm{HBV}$ and $\mathrm{HCV}$ infection. Cancer Lett. 2009;286:9-14.

98. Gandini S, Botteri E, Iodice S, et al. Tobacco smoking and cancer: a meta-analysis. Int $J$ Cancer. 2008;122:155-164.

99. International Agency for Research on Cancer. Tobacco Smoke and Involuntary Smoking. IARC Monographs on the Evaluation of the Carcinogenic Risks to Humans. Vol 83. Lyon: IARC; 2004:1-1438.

100. Maheswari S, Sarraj A, Kramer J, et al. Evidence at this time is inconclusive to establish the relation between oral contraceptive steroids and risk of hepatocellular carcinoma. J Hepatol. 2007;47:506-513.

\section{Publish your work in this journal}

The Journal of Hepatocellular Carcinoma is an international, peerreviewed, open access journal that offers a platform for the dissemination and study of clinical, translational and basic research findings in this rapidly developing field. Development in areas including, but not limited to, epidemiology, vaccination, hepatitis therapy, pathology and molecular tumor classification and prognostication are all considered for publication. The manuscript management system is completely online and includes a very quick and fair peer-review system, which is all easy to use. Visit http://www.dovepress.com/testimonialsphp to read real quotes from published authors.

Submit your manuscript here: http://www.dovepress.com/journal-of-hepatocellular-carcinoma-journal 